\title{
Metabolism of HDL apolipoprotein A-I and A-II in Type 1 (insulin-dependent) diabetes mellitus
}

\author{
M.-R. Taskinen ${ }^{1}$, J.Kahri ${ }^{1}$, V.Koivisto ${ }^{2}$, J.Shepherd ${ }^{3}$ and C. J.Packard $^{3}$ \\ ${ }^{1}$ Third and ${ }^{2}$ Second Departments of Medicine, University of Helsinki, Finland and the \\ ${ }^{3}$ Institute of Biochemistry, Royal Infirmary, Glasgow, Scotland, UK
}

\begin{abstract}
Summary. Concentrations of HDL cholesterol and apolipoprotein A-I are commonly increased in Type 1 (insulindependent) diabetes mellitus but the mechanisms whereby diabetes influences HDL metabolism have not been studied. We investigated the metabolism of HDL apoproteins A-I and II in normolipidaemic Type 1 diabetic men $(n=17$, $\mathrm{HbA}_{1} 6.4-11.9 \%$ ) without microalbuminuria but with a wide range of HDL cholesterol $(0.85-2.10 \mathrm{mmol} / \mathrm{l})$ and in nondiabetic men $(n=18)$ matched for body mass index and the range of HDL cholesterol. Input rates and fractional catabolic rates for apolipoproteins A-I and II were determined following injection of ${ }^{125} \mathrm{I}$-apolipoprotein A-I and ${ }^{131} \mathrm{I}$-apolipoprotein A-II tracers. Additional multicompartmental analysis was performed using a model to describe the kinetics of HDL particles containing only apolipoprotein A-I (Lp A-I) and apolipoprotein A-I and apolipoprotein A-II (Lp A-I/ A-II). No gross differences from normal subjects were observed in the mean levels of lipids, lipoproteins, apoproteins and the lipolytic enzymes in the diabetic men as a result of the selection process. Furthermore, the relationship between
\end{abstract}

apolipoprotein A kinetics and plasma HDL cholesterol levels appeared to be preserved in the diabetic group. However, some normal interrelationships were disrupted in the diabetic men. Firstly, the rate of apolipoprotein A-II synthesis was $22 \%$ lower than in control subjects $(p<0.05)$. Modelling indicated that this was due to decreased input of Lp A-I/A-II particles whereas the input of Lp A-I particles was similar in the two groups. Secondly, there was no correlation between VLDL triglyceride and HDL cholesterol or VLDL triglyceride and the fractional catabolic rate of apolipoproteins A-I and A-II in diabetic men in contrast to that seen in control subjects. We conclude that there is a disruption in the normal association between VLDL and HDL metabolism in Type 1 diabetic men and postulate that the observed differences may be due to the therapeutic use of exogenous insulin.

Key words: Type 1 (insulin-dependent) diabetes mellitus, HDL cholesterol, apolipoprotein A-I, apolipoprotein A-II, kinetic analyses, VLDL triglyceride, lipolytic enzymes.
A reduced $\mathrm{HDL}$ cholesterol level in plasma is a recognised risk factor for coronary heart disease [1]. The concentration and composition of this lipoprotein are regulated by the combined actions of a number of factors including lipoprotein lipase (LPL), hepatic lipase (HL) and cholesteryl-ester transfer protein (CETP) [2,3]. In addition plasma HDL levels are known to be influenced by changes in the synthesis and catabolism of the major HDL proteins, apolipoproteins (apo) A-I and A-II. HDL turnover studies have shown that the fractional catabolic rate (FCR) of apo A-I correlates inversely with the HDL levels in the circulation [4-7], i.e. a slow apo A-I FCR is associated with a high concentration of apo A-I and HDL. In contrast, fast clearance of apo A-I leads to low HDL levels regardless of the presence or absence of hypertriglyceridaemia [7-9].

Since coronary heart disease is the principal complication and leading cause of death in diabetes, HDL has been a focus of great interest in both the insulin-dependent and non-insulin-dependent forms of the condition. In general HDL cholesterol is lower in Type 2 (non-insulin-dependent) patients compared to non-diabetic populations matched for sex, age and body mass index [10]. Conversely, most studies have reported that in Type 1 diabetic patients with fair to good glycaemic control, the concentration of HDL cholesterol is either increased or normal [10]. Lowering of HDL cholesterol has been documented in two studies [11, 12]. Thus, the response of HDL in diabetes seems to be variable. The observed elevation of HDL cholesterol in Type 1 diabetes is mainly due to high levels of $\mathrm{HDL}_{2}$ but a rise of $\mathrm{HDL}_{3}$ has also been reported [13-16]. Not unexpectedly, therefore, the concentration of apo A-I in the plasma is generally elevated whereas that of apo A-II seems to be within the normal range [17-19]. Hyper-apo A-I is considered to be anti-atherogenic [3]. The apo A-I/A-II ratio rises consistently with a preferen- 
tial elevation of $\mathrm{HDL}_{2}$ which is the anti-atherogenic subclass of HDL cholesterol $[3,10]$. Consequently there is an unsolved paradox in Type 1 diabetes which is in general associated with an increased risk of coronary heart disease. Overall the mechanisms by which diabetes modify HDL metabolism are not fully understood. We have shown that in Type 1 diabetes, as in the non-diabetic population, lipolytic enzymes (LPL and HL) regulate plasma $\mathrm{HDL}_{2}$ [14]. The observed elevation of $\mathrm{HDL}_{2}$ cholesterol can be at least partly explained by a rise of LPL activity due to peripheral hyperinsulinism in conventionally treated Type 1 diabetes [20]. However, there are no reports on the metabolism of apo A-I and A-II in Type 1 diabetic patients.

In the present study we have examined in vivo the turnover of apo A-I and A-II in normolipidaemic Type 1 diabetic subjects with fair to good glycaemic control and a wide range of HDL cholesterol. In particular, we sought to determine whether the diabetic condition per se influenced HDL metabolism in Type 1 diabetes. Consequently, the patients were compared to non-diabetic control subjects with a similar wide range of HDL levels. In addition, we measured the activities of lipolytic enzymes (LPL and HL) in post-heparinized plasma.

\section{Subjects and methods}

Seventeen Type 1 diabetic men selected to provide a wide range of HDL cholesterol $(0.85-2.10 \mathrm{mmol} / 1)$ but with normal serum triglyceride concentrations $(<2.5 \mathrm{mmol} / \mathrm{l})$ participated in the study. The average age of the patients was $36 \pm 2$ years (mean $\pm S E M$, range 23-59 years) and the mean body mass index ranged from 18.1 to $27.4 \mathrm{~kg} / \mathrm{m}^{2}$ (mean $\pm \mathrm{SEM}, 23.5 \pm 0.6 \mathrm{~kg} / \mathrm{m}^{2}$ ). The duration of diabetes averaged $10.6 \pm 1.8$ years (range $2-25$ years). Sixteen patients received insulin by injection, two $(n=5)$ to three $(n=11)$ times daily and in one patient it was administered subcutaneously via a pump. The average dose of daily insulin was $41 \pm 3$ IU which remained constant throughout the study. The concentrations of $\mathrm{HbA}_{1}$ and fructosamine ranged from 6.4 to $11.9 \%$ and 2.2 to $3.9 \mu \mathrm{mol} / 1$ respectively. All the patients had C-peptide values of less than $0.33 \mathrm{nmol} / \mathrm{l}$. Overnight albumin excretion rates $(3-18 \mu \mathrm{g} / \mathrm{min})$ were normal as was the mean serum creatinine at $94 \pm 11$ (mean \pm SEM) $\mu$ mol/l. Two patients had background retinopathy. None was taking lipid-lowering drugs or other drugs known to influence lipid metabolism. The patients were instructed to follow a weight-maintaining, sucrose-free diet containing $45 \%$ of its calories as carbohydrate, $35 \%$ as fat and $20 \%$ as protein. The patients were recruited from the Diabetes Clinic of the Helsinki University Central Hospital.

Control men $(n=18)$ were recruited from volunteers screened for the Helsinki Heart Study between 1982 and 1983 but excluded from the study because their non-HDL cholesterol was $<5.2$ $\mathrm{mmol} / \mathrm{l}$. A subgroup $(n=92)$ of these men living in the Helsinki area were screened again in 1988. The control group was selected to have similar ranges of HDL cholesterol and serum triglyceride as the Type 1 diabetic patients. None had a history of cardiovascular disease. Endocrine and other disorders which could influence lipoprotein metabolism were excluded by medical history, clinical examination and liver, kidney and thyroid function tests. None of the subjects was taking any medication. The absence of diabetes was confirmed by measurement of fasting blood glucose and serum fructosamine. All clinical and laboratory work was completed in Helsinki whereas the kinetic analyses of apo A-I and A-II were performed in Glasgow. The study protocol was approved by the Ethical Committee of Helsinki University Hospital and informed consent was obtained from each subject.
Purification and labelling of apolipoprotein A-I and A-II

Heterologous apo A-I and A-II were used to guarantee the same batch and structure of apoprotein. Apo A-I and A-II were prepared in Glasgow from the plasma of healthy donors, who were negative on screening for hepatitis $B$ and human immunodeficiency virus. HDL was separated by ultracentrifugation and apo A-I and A-II prepared after delipidation and purification using high performance liquid chromatography as described previously [21]. The purity of apoproteins was established by a battery of immunoassays and by amino acid analysis [22]. The isolated apoproteins were dialysed against $0.1 \mathrm{~mol} / 1 \mathrm{NH}_{4} \mathrm{HCO}_{3}(\mathrm{pH} \mathrm{8.6})$, lyophilized and stored at $-70^{\circ} \mathrm{C}$. Batches of lyophilized apo A-I and A-II were mailed to Helsinki in dry ice and stored at $-70^{\circ} \mathrm{C}$. Apo A-I $(0.5 \mathrm{mg})$ and apo A-II $(0.5 \mathrm{mg})$ were trace labelled with $1 \mathrm{mCi}$ of ${ }^{123} \mathrm{I}$ and $1 \mathrm{mCi}^{131} \mathrm{I}$ respectively, by the iodine monochloride method [21, 23]. Radioiodinated apoproteins were freed from unbound radioiodide by column chromatography (Sephadex G-25M, Pharmacia, Uppsala, Sweden) and used immediately.

\section{Kinetic studies}

The subjects were examined as out-patients to avoid disruption of their daily life. No alcohol intake was allowed during the study and the subjects were instructed to maintain their normal physical activity. For 3 days before and throughout the study the subjects received potassium iodide ( $60 \mathrm{mg}$, three times per day) to minimise thyroid absorption of radioactive iodide.

Fasting blood was drawn into sterile tubes containing $300 \mu \mathrm{l}$ of $0.40 \mathrm{~mol} / \mathrm{l}$ disodium-EDTA solution in $80 \mathrm{ml}$ samples. Plasma $(25 \mathrm{ml})$ was adjusted to a density of $1.063 \mathrm{~g} / \mathrm{ml}$ by adding solid $\mathrm{KBr}$ and centrifuged in a Beckman Ti 60 rotor $(24 \mathrm{~h}, 40000 \mathrm{rev} / \mathrm{min}$, $4^{\circ} \mathrm{C}$ ). The top fraction containing VLDL, interme diate density lipoprotein (IDL) and LDL was removed and the density of the bottom adjusted to $1.210 \mathrm{~g} / \mathrm{ml}$ by addition of solid $\mathrm{KBr}$. HDL was isolated by a further centrifugation for $24 \mathrm{~h}$ as above. The HDL fraction was harvested by aspiration of $1-2 \mathrm{ml} \mathrm{samples}$ and stored at $4^{\circ} \mathrm{C}$ for up to $1-2 \mathrm{~h}$. ${ }^{125}$ I-labelled apo A-I and ${ }^{131}$ I-labelled apo A-II were incubated with $0.5-1 \mathrm{ml}$ of the HDL of each subject for $30 \mathrm{~min}$ at room temperature. The density of the incubation mixtures was adjusted to $1.21 \mathrm{~g} / \mathrm{ml}$ by using solid $\mathrm{KBr}$, overlayered with $3.5 \mathrm{ml}$ of $\mathrm{KBr}$ solution (density $=1.210 \mathrm{~g} / \mathrm{ml}$ ) and the HDL re-isolated by ultracentrifugation for $21 \mathrm{~h}$ at $40000 \mathrm{rev} / \mathrm{min}$ at $4^{\circ} \mathrm{C}$ in a Beckman Ti 50.3 rotor. ${ }^{125} \mathrm{I}$ apo A-I HDL and ${ }^{131} \mathrm{I}$ apo A-II HDL were harvested by aspiration and dialysed extensively against sterile $0.15 \mathrm{~mol} / 1 \mathrm{NaCl}, 0.01 \%$ disodium-EDTA. Thereafter the preparations were sterilised by membrane filtration $(0.22 \mu \mathrm{mol}$ Millipore filters, Millipore, Bedford, Mass., USA).

On the fifth morning after the collection of the initial blood samples the subjects received $25 \mu \mathrm{Ci}$ each of labelled apo A-I HDL and apo A-II HDL by i.v. bolus injection. The first blood sample was taken after $10 \mathrm{~min}$ and then daily after a 10 -h overnight fast until day 13. 24-h urine specimens were collected over 13 days and the urine volume measured. The concentration of creatinine in the urine was used as an index of completeness of collection. The radioactivity was measured in 2-ml aliquots of plasma and urine, and was counted at the end of the study.

\section{Lipid, lipoprotein and apoprotein determinations}

On days 1, 6,10 and 13 of the turnover period blood was drawn after a 10-h overnight fast for measurement of serum lipids and lipoproteins. Lipoprotein fractions were isolated by sequential ultracentrifugation [24] in a Beckman L7-70 ultracentrifuge (Beckman Instruments, Palo Alto, Calif., USA) using a Kontrol TZT 45.6 rotor (Kontron AG, Basel, Switzerland). VLDL, IDL and LDL were isolated at densities of $1.006,1.019$ and $1.063 \mathrm{~g} / \mathrm{ml}$, respectively. Thereafter, $\mathrm{HDL}_{2}$ and $\mathrm{HDL}_{3}$ were isolated at densities of 1.125 and 


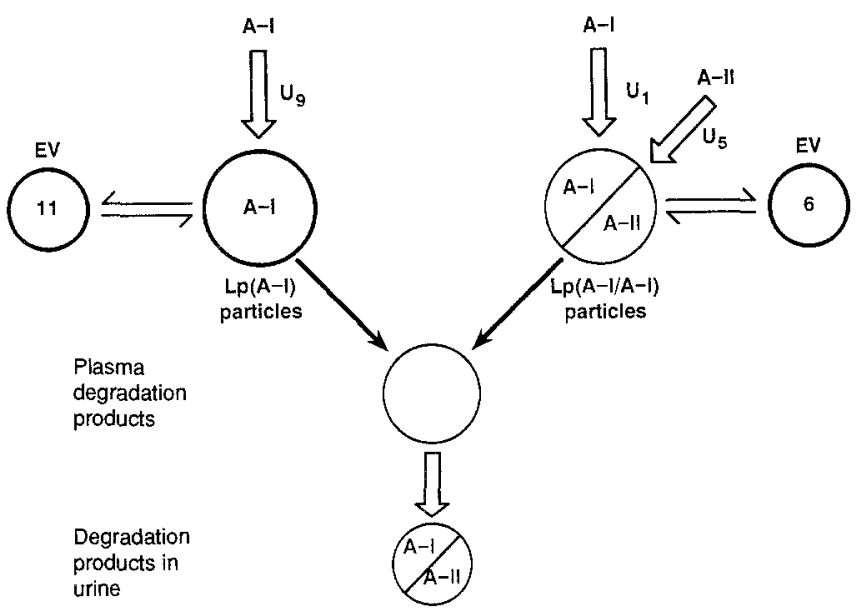

Fig. 1. A kinetic model for the metabolism of HDL particles containing apolipoprotein (apo) A-I and A-II (LpA-I/A-II) and apo A-I only (LpA-I). $\mathrm{U}_{9}$ and $\mathrm{U}_{1}$ indicate the inputs of apo A-I into compartments $M_{9}$ and $M_{1}$ respectively. $U_{5}$ indicates the input of apo A-II into compartment $\mathrm{M}_{5} . \mathrm{EV}$ indicates extravascular space

$1.210 \mathrm{~g} / \mathrm{ml}$ using centrifugation times of $48 \mathrm{~h}$ at $38000 \mathrm{rev} / \mathrm{min}$. The concentrations of triglycerides, cholesterol, phospholipids and protein were measured in each fraction. Apo A-I and A-II were assayed from daily samples by immunoturbidometry using monospecific antibodies (nos 726478 and 726486, Boehringer Mannheim GmbH, Mannheim, FRG). The interassay coefficient of variation of apo A-I and A-II assays were $4.3 \%$ and $5.3 \%$ respectively.

\section{Post-heparin plasma LPL and hepatic lipase}

After collection of the blood sample for HDL isolation, heparin (100 IU/kg body weight, Leiras, Huhtamäki Oy, Turku, Finland) was injected i.v. as a bolus, and blood was drawn before and 15 min after the injection into chilled heparinized tubes kept on ice. Plasma was separated immediately in a cooled centrifuge and stored at $-20^{\circ} \mathrm{C}$. LPL and hepatic lipase activities were measured by an immunochemical method using a specific antiserum against hepatic lipase in the LPL assay [25]. Hepatic lipase was measured with a substrate containing $1 \mathrm{~mol} / \mathrm{l} \mathrm{NaCl}$ to inactivate the LPL. Each assay series included two reference standards for LPL and HL activities.

\section{Analysis of apo A-I and A-II kinetics}

Kinetic analysis of the data was performed with the SAAM 20 program [26]. Radioactivity decay curves in plasma and urine, together with the mean masses of apo A-I and A-II were used to derive FCRs and inputs for the individual apoproteins. To gain further insight into apo A kinetics, the turnover data for apo A-I and apo A-II were combined according to the model shown in Figure 1. It is based on the observation that HDL can be divided into populations of particles containing apo A-I and apo A-II (LpA-I/A-II) and apo A-I alone (LpA-I) $[22,27]$. The following assumptions were made: (1) Lp A-I and Lp A-I/A-II HDL particles are metabolically distinct and have different input and output rates. (2) An HDL particle (LpA-I or LpA-I/A-II) is cleared as a unit with degradation of apoprotein. (3) The molar ratio of A-I to A-II in Lp A-I/A-II is about 1.0 .

\section{Rationale}

It has been a long-standing observation that tracer apo A-I is removed from the circulation more rapidly than apo A-II [4-6]. In an attempt to reconcile the behaviour of these major HDL proteins, Zech et al. [28] proposed a composite model in which apo A-II turn- over was explained by a single plasma compartment while apo A-I required two. The slower metabolised apo A-I pool had kinetic characteristics similar to those of apo A-II. Support for this view of HDL metabolism came from structural studies which revealed that two particle types were present in the HDL density interval, one containing apo A-I the other apo A-I and apo A-II $[22,27,29,30]$. A series of investigations using immunochemical [31], ultracentrifugal [32] and cross-linking [33] techniques have concluded that the measured molar ratio of apo A-I to apo A-II in LpA-I/A-II is invariant at about 1:1 provided that apo A-II represents a dimer. When measured immunochemically this ratio appears to be approximately $1.3: 1$, possibly as a result of differential antigenic expression of the apoproteins, giving a weight ratio of 2.1:1. Assumption 3 noted above is, therefore, founded on a substantial body of experimental evidence.

${ }^{131}$ I apo A-II can be considered to trace the behaviour of LpA-I/ A-II particles assuming the particle is catabolised as a unit (assumption 2) and therefore the calculated FCR for apo A-II provides an FCR for its accompanying apo A-I. This together, the pool size for A-I in LpA-I/A-II derived from the apo A-I/A-II ratio yields an input rate $\left(\mathrm{U}_{9}\right)$.

Derivation of the kinetics of LpA-I is more problematic. There is a difference between apo A-I and A-II clearance as noted above which can be ascribed to differential catabolism of LpA-I and LpAI/A-II particles. If the interparticle exchange of apo A-I is ignored then the initial radioactivity of apo A-I tracer can be distributed according to the calculated mass of apo A-I in LpA-I/A-II and in LpAI (i. e. total apo A-I minus A-I in LpA-I/A-II). The fractional catabolic and input rates of LPA-I can then be derived using SAAM 30 and the model in Figure 1. LpA-I clearance is basically the difference between the behaviour of apo A-I in LpA-I/A-II and that of total apo A-I. If exchange of apo A-I between the two particle types takes place, then the differences between their catabolic rates are reduced and not adequately detected using the present technique. Therefore, the LpA-I kinetic data must be viewed with some caution and may be an underestimate. However, it is useful to apply the model in an attempt to understand more clearly the regulation of HDL metabolism in control and diabetic subjects.

\section{Analytical methods}

Blood glucose was measured by the glucose oxidase method (Autoanalyser, Technicon, Tarrytown, NY, USA). Serum free-insulin concentrations were determined by radioimmunoassay with Phadeseph insulin radioimmunoassay kits (Pharmacia, Uppsala, Sweden) after precipitation with polyethylene glycol [34]. Serum C-peptide (reference range $0.33-0.67 \mathrm{mmol} / \mathrm{l})$ was measured as described by Heding [35]. $\mathrm{HbA}_{1}$ (normal range 6-8.5\%), was measured by microcolumn chromatography (Isolab, Akron, Ohio, USA) [36] and fructosamine (reference range $2.0-2.8 \mathrm{mmol} / \mathrm{l}$ ) by the method of Johnson et al. [37]. The serum concentrations of cholesterol and triglycerides were determined with Boehringer Mannheim kits (nos 18313 and 297771) in a fully automated Olli-D discrete analyser (Kone, Helsinki, Finland).

\section{Statistical analysis}

The results are presented as mean $\pm \mathrm{SD}$. Data analysis were conducted with a Biomedical Data Processing program [38]. In comparision between the two groups Student's paired $t$-test (normal distribution) and the Mann-Whitney rank sum test (non-parametric test) were used (program 3D).

\section{Results}

\section{Metabolic parameters}

The diabetic patients exhibited a wide range of glycaemic control (Table 1). Fasting glucose concentrations over the 13-day turnover period ranged from 5.4 to $14.5 \mathrm{mmol} / \mathrm{l}$ 
Table 1. Plasma lipids and lipoproteins and lipolytic enzyme activities in Type 1 (insulin-dependent) diabetic men $(n=17)$ and in non-diabetic $\operatorname{men}(n=18)$

\begin{tabular}{|c|c|c|c|c|c|c|c|c|c|c|c|}
\hline \multirow{2}{*}{$\begin{array}{l}\text { Type } 1 \\
\text { diabetic } \\
\text { patients }\end{array}$} & \multirow{2}{*}{$\begin{array}{l}\text { Age } \\
\text { (years) }\end{array}$} & \multirow{2}{*}{$\begin{array}{l}\text { BMI } \\
\left(\mathrm{kg} / \mathrm{m}^{2}\right)\end{array}$} & \multirow{2}{*}{$\begin{array}{l}\text { Fasting } \\
\text { glucose } \\
(\mathrm{mmol} / \mathrm{l})\end{array}$} & \multicolumn{2}{|c|}{ 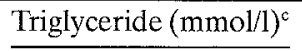 } & \multicolumn{4}{|c|}{ Cholesterol $(\mathrm{mmol} / 1)^{\mathrm{c}}$} & \multicolumn{2}{|c|}{ Post-heparin } \\
\hline & & & & Plasma & VLDL & Plasma & VLDL & LDL & $\overline{\mathrm{HDL}}$ & $\begin{array}{l}\text { LPL } \\
\text { ( } \mu \text { mol non- } \\
\text { fatty acids }\end{array}$ & $\begin{array}{l}\mathrm{HL} \\
\text {-esterified } \\
\left.\mathrm{ml}^{-1} \cdot \mathrm{h}^{-1}\right)\end{array}$ \\
\hline 1 & 43 & 24.6 & 6.8 & 1.01 & 0.31 & 6.31 & 0.09 & 4.00 & 2.09 & 52.4 & 24.9 \\
\hline 2 & 59 & 28.7 & 8.0 & 0.89 & 0.38 & 5.25 & 0.18 & 2.90 & 1.99 & 52.9 & 28.0 \\
\hline 3 & 43 & 26.1 & 11.3 & 0.77 & 0.29 & 5.47 & 0.05 & 3.26 & 1.99 & 32.0 & 22.8 \\
\hline 4 & 36 & 21.5 & 10.0 & 0.97 & 0.33 & 6.95 & 0.10 & 4.78 & 1.91 & 20.1 & 21.6 \\
\hline 5 & 30 & 24.8 & 8.7 & 0.60 & 0.18 & 5.52 & 0.07 & 3.59 & 1.82 & 32.6 & 19.7 \\
\hline 6 & 33 & 21.7 & 12.2 & 1.15 & 0.46 & 5.25 & 0.26 & 3.06 & 1.78 & 49.1 & 21.4 \\
\hline 7 & 30 & 21.6 & 12.3 & 1.33 & 0.75 & 6.22 & 0.35 & 4.13 & 1.72 & 22.3 & 31.9 \\
\hline 8 & 33 & 19.9 & 7.1 & 0.87 & 0.30 & 5.25 & 0.16 & 3.36 & 1.71 & 30.0 & 23.6 \\
\hline 9 & 37 & 21.3 & 6.5 & 0.77 & 0.34 & 4.47 & 0.16 & 2.57 & 1.64 & 31.4 & 30.4 \\
\hline 10 & 32 & 18.1 & 9.8 & 0.81 & 0.39 & 3.59 & 0.07 & 1.93 & 1.54 & 36.6 & 24.8 \\
\hline 11 & 37 & 26.0 & 10.6 & 1.55 & 0.75 & 6.24 & 0.88 & 3.72 & 1.34 & 31.3 & 29.4 \\
\hline 12 & 23 & 24.3 & 8.2 & 1.16 & 0.61 & 3.81 & 0.28 & 2.08 & 1.30 & 24.0 & 23.5 \\
\hline 13 & 55 & 21.3 & 11.9 & 2.02 & 0.99 & 8.06 & 0.43 & 6.04 & 1.24 & 27.2 & 22.1 \\
\hline 14 & 43 & 25.9 & 5.4 & 0.71 & 0.30 & 5.87 & 0.11 & 4.41 & 1.24 & 25.8 & 64.3 \\
\hline 15 & 25 & 22.1 & 14.5 & 0.85 & 0.39 & 3.72 & 0.17 & 2.37 & 1.17 & 43.3 & 27.5 \\
\hline 16 & 36 & 27.4 & 11.9 & 1.00 & 0.51 & 4.60 & 0.25 & 3.20 & 0.90 & 15.2 & 48.5 \\
\hline 17 & 30 & 22.7 & 9.2 & 0.86 & 0.41 & 3.39 & 0.08 & 2.30 & 0.84 & 32.0 & 35.4 \\
\hline Mean $\pm S$ & $37 \pm 10^{a}$ & $23.5 \pm 2.9$ & $9.7 \pm 2.5$ & $1.02 \pm 0.35$ & $0.45 \pm 0.21$ & $5.21 \pm 0.20$ & $0.21 \pm 0.20$ & $3.42 \pm 1.10$ & $1.55 \pm 0.39$ & $32.9 \pm 11.0$ & $29.4 \pm 11.3$ \\
\hline \multicolumn{12}{|c|}{ Control subjects } \\
\hline 1 & 53 & 20.3 & 4.7 & 0.95 & 0.43 & 5.12 & 0.11 & 2.26 & 2.66 & 31.1 & 35.1 \\
\hline 2 & 50 & 22.8 & 4.6 & 0.98 & 0.25 & 6.35 & 0.16 & 3.46 & 2.47 & 32.7 & 9.1 \\
\hline 3 & 51 & 21.3 & 4.8 & 1.30 & 0.63 & 5.43 & 0.60 & 2.22 & 2.37 & 39.1 & 12.8 \\
\hline 4 & 51 & 27.3 & 5.0 & 0.75 & 0.18 & 6.35 & 0.05 & 3.89 & 2.27 & 50.1 & 7.9 \\
\hline 5 & 54 & 25.2 & 4.4 & 0.58 & 0.19 & 6.26 & 0.10 & 3.96 & 2.16 & 52.9 & 28.0 \\
\hline 6 & 47 & 24.1 & 4.6 & 0.73 & 0.29 & 6.25 & 0.09 & 4.20 & 1.91 & 27.7 & 27.9 \\
\hline 7 & 49 & 26.7 & 4.7 & 0.83 & 0.28 & 5.88 & 0.12 & 3.87 & 1.76 & 24.9 & 29.8 \\
\hline 8 & 50 & 25.8 & 4.6 & 1.13 & 0.74 & 5.41 & 0.28 & 3.28 & 1.75 & 34.7 & 18.2 \\
\hline 9 & 49 & 20.3 & 4.4 & 0.83 & 0.46 & 4.76 & 0.18 & 2.89 & 1.61 & 12.5 & 45.5 \\
\hline 10 & 50 & 25.7 & 5.3 & 1.17 & 0.65 & 4.90 & 0.33 & 2.97 & 1.53 & 33.6 & 17.3 \\
\hline 11 & 53 & 26.9 & 5.0 & 2.50 & 1.66 & 7.00 & 0.57 & 4.83 & 1.33 & 16.2 & 28.6 \\
\hline 12 & 55 & 28.7 & 5.3 & 1.12 & 0.63 & 4.89 & 0.23 & 3.05 & 1.22 & 16.3 & 29.3 \\
\hline 13 & 25 & 26.9 & 4.8 & 1.23 & 0.75 & 4.24 & 0.19 & 2.85 & 1.11 & & \\
\hline 14 & 50 & 23.2 & 4.8 & 0.90 & 0.35 & 5.99 & 1.34 & 4.56 & 1.05 & 11.4 & 24.9 \\
\hline 15 & 32 & 28.1 & 4.6 & 1.80 & 1.14 & 6.74 & 0.53 & 4.86 & 1.04 & 37.2 & 70.9 \\
\hline 16 & 55 & 24.1 & 4.6 & 1.84 & 1.28 & 5.07 & 0.48 & 3.45 & 0.99 & 7.2 & 35.6 \\
\hline 17 & 55 & 31.1 & 4.6 & 1.86 & 1.13 & 4.84 & 0.87 & 2.93 & 0.72 & 19.2 & 24.0 \\
\hline 18 & 53 & 28.7 & 4.6 & 2.36 & 1.56 & 4.59 & 0.82 & 2.97 & 0.51 & 19.2 & 19.6 \\
\hline Mean $\pm S$ & $49 \pm 8$ & $25.4 \pm 3.0$ & $4.7 \pm 0.3$ & $1.27 \pm 0.56$ & $0.70 \pm 0.47$ & $5.53 \pm 0.83$ & $0.32 \pm 0.26$ & $3.47 \pm 0.79$ & $1.58 \pm 0.63$ & $29.8 \pm 16.1$ & $31.7 \pm 21.8$ \\
\hline
\end{tabular}

${ }^{\mathrm{a}} p<0.01$ compared to the control subjects; ${ }^{\mathrm{b}}$ The figures represent the mean of the daily measurements over 13 days; ${ }^{\mathrm{c}}$ The figures represent the mean of the measurement on days $1,6,10$ and 13 of the turnover period

(mean $\pm \mathrm{SD} 9.7 \pm 2.5 \mathrm{mmol} / \mathrm{l})$. The concentrations of $\mathrm{HbA}_{1 \mathrm{C}}$ and fructosamine averaged $8.9 \pm 1.7 \%$ (range 6.4 to $11.9 \%$ ) and $3.1 \pm 0.54 \mu \mathrm{mol} / 1$ (range 2.2 to $3.9 \mu \mathrm{mol} / \mathrm{l}$ ) respectively.

\section{Plasma lipids and lipoproteins}

There were no significant differences in the concentration of cholesterol in total plasma, VLDL and LDL between the two groups. The mean concentrations of $\mathrm{HDL}_{2}$ cholesterol and $\mathrm{HDL}_{3}$ cholesterol were $1.03 \pm 0.35$ and $0.52 \pm 0.14 \mathrm{mmol} / 1$ in Type 1 diabetic patients and $1.06 \pm 0.56$ and $0.52 \pm 0.16 \mathrm{mmol} / \mathrm{l}$ in control men respectively. The concentration of triglycerides in total plasma and VLDL was lower in Type 1 diabetic patients than in non-diabetic men but LDL and HDL triglycerides did not differ between the groups.

\section{Concentrations of apolipoprotein $A$ - I and A-II}

Mean values and plasma pools of apo A-I did not differ between the diabetic patients and the control subjects (Table 2). The concentration of A-II tended to be less in Type 1 diabetic men than in control subjects but the difference did not reach statistical significance. The HDL cholesterol/(apo A-I + apo A-II) ratio and the apo A-I/apo A-II ratio were calculated as indexes of the composition of HDL. The HDL cholesterol/A-I + A-II ratio was similar in the two groups $(0.36 \pm 0.05$ in Type 1 diabetic subjects vs $0.34 \pm 0.08$ in control subjects, NS) while the 
Table 2. Calculated pool sizes $(\mathrm{mg}$ ) computed compartment masses ( $\mathrm{mg}$ ), input rates and fractional catabolic rates (FCR) in Type 1 (insulindependent) diabetic men $(n=17)$ and in non-diabetic men $(n=18)$

\begin{tabular}{|c|c|c|c|c|c|c|}
\hline \multirow[t]{2}{*}{ Type 1 diabetic patients } & \multirow{2}{*}{$\begin{array}{l}\text { Plasma apo A-I } \\
(\mathrm{mg} / \mathrm{dl})\end{array}$} & \multirow{2}{*}{$\begin{array}{l}\text { Plasma apo A-II } \\
(\mathrm{mg} / \mathrm{dl})\end{array}$} & \multicolumn{2}{|c|}{ FCR (pools/day) } & \multicolumn{2}{|c|}{ Input rates $\left(\mathrm{mg} \cdot \mathrm{kg}^{-1} \cdot\right.$ day $\left.^{-1}\right)$} \\
\hline & & & apo A-I & apo A-II & apo A-I & apo A-II \\
\hline 1 & 158 & 32.2 & 0.116 & 0.130 & 7.32 & 1.73 \\
\hline 2 & 154 & 28.6 & 0.130 & 0.159 & 8.04 & 1.82 \\
\hline 3 & 172 & 34.4 & 0.116 & 0.137 & 8.00 & 1.89 \\
\hline 4 & 166 & 34.1 & 0.138 & 0.119 & 8.82 & 1.63 \\
\hline 5 & 160 & 27.7 & 0.128 & 0.142 & 8.17 & 1.57 \\
\hline 6 & 151 & 42.4 & 0.176 & 0.164 & 10.60 & 2.79 \\
\hline 7 & 134 & 30.1 & 0.154 & 0.149 & 8.71 & 1.88 \\
\hline 8 & 125 & 34.5 & 0.162 & 0.159 & 8.11 & 2.18 \\
\hline 9 & 125 & 24.1 & 0.136 & 0.150 & 6.76 & 1.46 \\
\hline 10 & 127 & 21.2 & 0.157 & 0.167 & 7.98 & 1.39 \\
\hline 11 & 132 & 33.3 & 0.187 & 0.185 & 8.60 & 2.47 \\
\hline 12 & 131 & 31.8 & 0.187 & 0.175 & 9.80 & 2.21 \\
\hline 13 & 140 & 40.0 & 0.187 & 0.190 & 10.48 & 3.05 \\
\hline 14 & 106 & 29.8 & 0.206 & 0.185 & 8.75 & 2.19 \\
\hline 15 & 119 & 24.9 & 0.214 & 0.196 & 10.17 & 1.97 \\
\hline 16 & 98 & 20.4 & 0.277 & 0.235 & 10.90 & 1.91 \\
\hline 17 & 96 & 23.4 & 0.211 & 0.198 & 8.07 & 1.84 \\
\hline Mean \pm SD & $135 \pm 23$ & $30.2 \pm 6.2$ & $0.169 \pm 0.042$ & $0.167 \pm 0.029$ & $8.52 \pm 1.62$ & $2.00 \pm 0.45^{a}$ \\
\hline \multicolumn{7}{|l|}{ Control subjects } \\
\hline 1 & 189 & 34.6 & 0.136 & 0.151 & 10.29 & 2.09 \\
\hline 2 & 212 & 57.5 & 0.162 & 0.162 & 13.77 & 3.73 \\
\hline 3 & 200 & 35.9 & 0.158 & 0.174 & 13.13 & 2.57 \\
\hline 4 & 153 & 30.6 & 0.092 & 0.104 & 5.36 & 1.27 \\
\hline 5 & 167 & 39.1 & 0.161 & 0.172 & 10.80 & 2.68 \\
\hline 6 & 147 & 28.0 & 0.130 & 0.160 & 7.46 & 1.79 \\
\hline 7 & 138 & 38.6 & 0.181 & 0.162 & 10.00 & 2.50 \\
\hline 8 & 146 & 41.1 & 0.157 & 0.164 & 9.14 & 2.70 \\
\hline 9 & 137 & 31.1 & 0.163 & 0.165 & 8.91 & 2.07 \\
\hline 10 & 133 & 38.9 & 0.128 & 0.142 & 6.83 & 2.21 \\
\hline 11 & 116 & 32.4 & 0.201 & 0.184 & 9.29 & 2.40 \\
\hline 12 & 122 & 32.8 & 0.185 & 0.179 & 9.02 & 2.30 \\
\hline 13 & 106 & 26.8 & 0.241 & 0.230 & 10.26 & 2.46 \\
\hline 14 & 93 & 24.1 & 0.239 & 0.223 & 8.92 & 2.13 \\
\hline 15 & 117 & 36.3 & 0.235 & 0.216 & 11.07 & 3.13 \\
\hline 16 & 101 & 30.8 & 0.202 & 0.201 & 8.10 & 2.47 \\
\hline 17 & 109 & 23.4 & 0.317 & 0.227 & 13.76 & 2.17 \\
\hline 18 & 98 & 26.6 & 0.324 & 0.295 & 12.80 & 3.16 \\
\hline Mean $\pm S D$ & $138 \pm 35$ & $33.9 \pm 8.0$ & $0.190 \pm 0.062$ & $0.184 \pm 0.043$ & $9.45 \pm 2.35$ & $2.43 \pm 0.55$ \\
\hline
\end{tabular}

${ }^{\mathrm{a}} p<0.01$ compared to control subjects; ${ }^{\mathrm{b}}$ The figures represent the mean of the daily measurements over 13 days

A-I/A-II ratio tended to be higher in the diabetic men $(4.55 \pm 0.78$ vs $4.11 \pm 0.75)$ than in the control subjects.

\section{Apolipoprotein A-I and A-II metabolism}

The mean fractional clearance for apo A-I and apo A-II were not significantly different between the Type 1 diabetic and control groups although they tended to be lower in the former (Table 2). Calculation of input rates showed that Type 1 diabetic men produced the same amount of apo A-I as control subjects but significantly less apo A-II. Examination of individual pairs of apo A-I and apo A-II turnovers (Table 2) revealed that (1.) the FCR for apo A-I was in some subjects greater than and in others less than that for apo A-II, and (2.) the relationship of apo A-I and apo A-II clearance was linked to the relative abundance of these apoproteins in plasma. As shown in Figure 2 when the plasma apo A-I level was low, its clearance exceeded that of apo A-II while the converse was true at high apo A-I levels. Near the population mean value for the plasma concentration of these apoproteins (middle panel), the decay rates for A-I and A-II were virtually identical. These observations cannot be explained unless the tracers are envisaged as being unequally distributed within the HDL spectrum as conceived in the model in Figure 1. If it is accepted that ${ }^{131} \mathrm{I}$ apo A-II traces the LpA-I/A-II particle and the LpA-I behaves independently then it is possible to derive additional kinetic parameters for these particles as shown in Table 3. While LpA-I/A-II clearance is relatively constant in both groups the rate of LpA-I catabolism is more variable and may be less or greater than that of LpA-I/A-II. Subjects with a higher total plasma apo A-I concentration have higher levels of LpA-I and a slower clearance of this particle (Table 3). When the data from all 35 subjects were combined (Fig.3) and divided in tertiles of LpA-I FCR, it could be seen that those in the lowest tertile had high concentrations of $\mathrm{HDL}_{2}$ cholesterol and plasma apo A-I and relatively larger HDL (based on the HDL cholesterol/ 


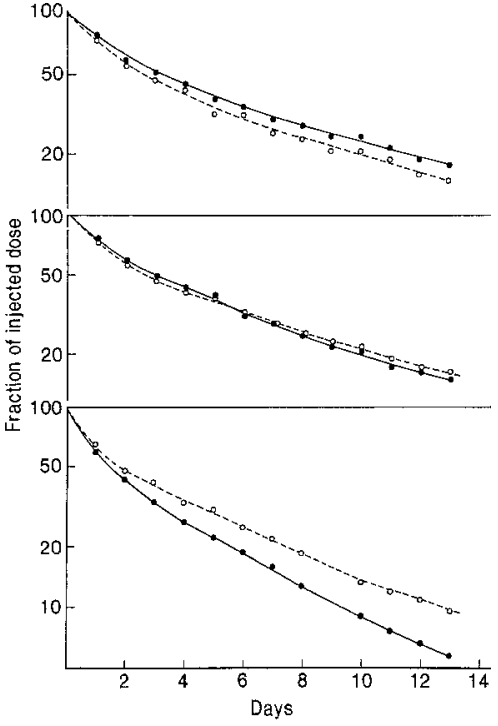

Fig. 2. Radioactive decay curves of ${ }^{125}$ I-labelled apolipoprotein (apo) A-I and ${ }^{131} \mathrm{I}$-labelled apo A-II in three individuals with either high (apo A-I $=156 \mathrm{mg} / \mathrm{dl}$ and apo A-II $=29 \mathrm{mg} / \mathrm{dl}$, upper panel), moderate (apo $\mathrm{A}-\mathrm{I}=137 \mathrm{mg} / \mathrm{dl}$ and apo $\mathrm{A}-\mathrm{II}=31 \mathrm{mg} / \mathrm{dl}$, middle panel) or low (apo A-I $=109 \mathrm{mg} / \mathrm{dl}$ and apo A-II $=24 \mathrm{mg} / \mathrm{dl}$, lower panel) plasma concentration of apo A-I

A-I + A-II ratio). Mean values for apo A input rate for the Type 1 diabetic patients and control subjects are given in Table 3. The input of apo A-I and LpA-I particles ( $\mathrm{U}_{9}$, Table 3, Figs. 1 and 4 ) was similar in the two groups. In contrast, the input rates for apo A-I $\left(\mathrm{U}_{1}\right.$, Figs. 1 and 4$)$ and apo A-II ( $\mathrm{U}_{5}$, Figs. 1 and 4$)$ into LpA-I/A-II were reduced in Type 1 diabetic patients.

\section{Interrelations between apo A metabolism and plasma $H D L$ and $V L D L$ levels}

HDL cholesterol correlated inversely with FCRs of apo A-I, apo A-II ( $r=-0.91$ in Type 1 diabetic patients, $r=-0.83$ in control subjects; $p<0.001$ in both groups) and the calculated FCR for LpA-I $(r=-0.08$ in Type 1 diabetic patients, $r=-0.72$ in control subjects, $p<0.001$ in both groups). These correlations were accounted for by the variation of $\mathrm{HDL}_{2}$ but not $\mathrm{HDL}_{3}$. There was no association between HDL cholesterol levels and any of the input rates for apo A-I or apo A-II in non-diabetic or Type 1 diabetic men (Tables 2 and 3 ). The concentration of apo A-I was determined by the rate of catabolism of the protein (plasma apo A-I vs apo A-I FCR, $r=-0.82$, $p<0.001$ in Type 1 diabetic patients and $r=-0.64$, $p<0.01$ in control subjects) whereas that of apo A-II was governed largely by its synthesis (apo A-II vs A-II input $\mathrm{mg} \cdot \mathrm{kg}^{-1} \cdot \mathrm{day}^{-1}, r=0.72, p<0.01$ in Type 1 diabetic patients and $r=0.59, p<0.01$ in control subjects). HDL cholesterol varied in an inverse fashion with VLDL triglyceride $(r=-0.70, p<0.01$, Table 1$)$ in non-diabetic subjects but not in Type 1 diabetic men $(r=-0.38, \mathrm{NS})$. This dichotomy persisted when the strength of the relationship between VLDL triglyceride and apo A clearance was examined. In non-diabetic men a significant positive correlation existed between the apo A-I and apo A-II FCR and VLDL triglyceride concentration (Fig. 5) but this was absent in the Type 1 diabetic group. In contrast, a positive relationship was seen between VLDL triglyceride and apo A-I or apo A-II input rates $\left(\mathrm{mg} \cdot \mathrm{kg}^{-1}\right.$. day $\left.^{-1}\right)(r=+0.49, p<0.05, r=+0.67, p<0.01)$ in Type 1 diabetic men but non-diabetic in normal men $(r=0.24$, $r=0.29$, NS).

\section{Lipolytic enzymes, HDL and apo A metabolism}

Mean values of LPL and HL were similar in control subjects and Type 1 diabetic men (Table 1 ). The concentration of VLDL triglyceride was inversely correlated with LPL activity in the control group $(r=-0.46, p<0.05)$ but not in the Type 1 diabetic group ( $r=-0.29$, NS). In both groups $\mathrm{HDL}_{2}$ cholesterol was positively related to LPL activity $(r=+0.51, p<0.05$ in Type 1 diabetic patients; $r=+0.66, p<0.01$ in control subjects) but only in Type 1 diabetic men was it inversely related to HL activity $(r=$ $-0.58, p<0.05$ vs $r=-0.26$, NS in control subjects). However, an inverse association existed between $\mathrm{HDL}_{2}$ triglycerides and HL activity in both groups $(r=-0.58$, $p<0.05$ and $r=-0.53, p<0.05$ ). The two lipases have opposite actions on HDL size and composition and their ratio was calculated to examine their relative impact. The mean LPL/HL ratio did not differ between control subjects and Type 1 diabetic men but was positively correlated with the $\mathrm{HDL}_{2}$ cholesterol in both groups $(r=+0.67, p<0.01$ and $r=+0.60, p<0.05)$. High LPL activity was found in those control subjects with slow clearance rates for apo A-I and apo A-II (LPL vs apo A-I FCR, $r=-0.49, p<0.05$, LPL vs apo A-II FCR, $r=-0.47, p<0.05)$. This relationship was absent in the Type 1 diabetic group. The LPL/HL ratio correlated inversely with the FCR of apo A-I in Type 1 diabetic men and in control subjects $(r=-0.54, p<0.05$ and $r=-0.51$, $p<0.05$ ).

\section{The impact of glycaemic control on apo A-I and apo A-II} metabolism

In Type 1 diabetic men neither the concentrations of fructosamine or glycosylated haemoglobin were related to the concentrations of VLDL triglyceride $(r=-0.07$, NS and $r=-0.33$, NS) or HDL cholesterol $(r=0.42$, NS and $r=0.40, \mathrm{NS}$ ) respectively. Overall there were no relationships between the FCR's and input rates of apo A-I and A-II and values of fructosamine or glycosylated haemoglobin. No significant correlations were found between daily insulin dose and parameters of apo A-I and A-II metabolism.

\section{Discussion}

The present study was designed specifically to look for subtle abnormalities in the regulation of apo A metabolism in Type 1 diabetes. To achieve this we matched the 
Table 3. Compartment masses $(\mathrm{mg})$, input rates $\left(\mathrm{mg} \cdot \mathrm{kg}^{-1} \cdot\right.$ day ${ }^{-1}$ ) and fractional catabolic rate (FCR) of apo Lp (A-I) computed by using the predicted model shown in Figure 1

\begin{tabular}{|c|c|c|c|c|c|}
\hline \multirow[t]{2}{*}{ Type 1 diabetic patients } & \multirow{2}{*}{$\begin{array}{l}\text { FCR (pools/day) } \\
\text { apo Lp (A-I) }\end{array}$} & \multicolumn{2}{|c|}{ Compartment masses (mg) } & \multicolumn{2}{|c|}{ Input rates $\left(\mathrm{mg} \cdot \mathrm{kg}^{-1} \cdot \mathrm{day}^{-1}\right)$} \\
\hline & & $\mathrm{M}_{1}$ & $\mathrm{M}_{9}$ & $\mathrm{U}_{1}$ & $\mathrm{U}_{9}$ \\
\hline 1 & 0.105 & 2169 & 2760 & 3.62 & 3.71 \\
\hline 2 & 0.112 & 2215 & 3465 & 3.83 & 4.22 \\
\hline 3 & 0.099 & 2398 & 3052 & 4.15 & 3.85 \\
\hline 4 & 0.143 & 1772 & 2348 & 3.40 & 5.42 \\
\hline 5 & 0.119 & 1890 & 3360 & 3.28 & 4.89 \\
\hline 6 & 0.193 & 2560 & 1779 & 5.83 & 4.76 \\
\hline 7 & 0.159 & 1593 & 1797 & 3.95 & 4.75 \\
\hline 8 & 0.167 & 1914 & 1386 & 4.59 & 3.52 \\
\hline 9 & 0.125 & 1292 & 1859 & 3.08 & 3.68 \\
\hline 10 & 0.151 & 1141 & 2119 & 2.97 & 5.02 \\
\hline 11 & 0.141 & 2430 & 2430 & 4.88 & 3.72 \\
\hline 12 & 0.200 & 2274 & 2185 & 4.67 & 5.14 \\
\hline 13 & 0.182 & 1950 & 1300 & 6.40 & 4.09 \\
\hline 14 & 0.237 & 2030 & 1410 & 4.63 & 4.12 \\
\hline 15 & 0.227 & 1360 & 1730 & 4.11 & 6.06 \\
\hline 16 & 0.197 & 1382 & 1758 & 6.56 & 4.34 \\
\hline 17 & 0.225 & 1484 & 1426 & 3.86 & 4.21 \\
\hline Mean \pm SD & $0.164 \pm 0.042$ & $1874 \pm 438$ & $2128 \pm 687$ & $4.34 \pm 1.08^{\mathrm{a}}$ & $4.44 \pm 0.71$ \\
\hline \multicolumn{6}{|l|}{ Control subjects } \\
\hline 1 & 0.127 & 1624 & 2605 & 4.38 & 5.91 \\
\hline 2 & 0.163 & 3590 & 2600 & 7.95 & 5.82 \\
\hline 3 & 0.149 & 1814 & 2986 & 5.48 & 7.72 \\
\hline 4 & 0.084 & 1991 & 2749 & 2.66 & 2.97 \\
\hline 5 & 0.152 & 2166 & 2254 & 5.62 & 5.18 \\
\hline 6 & 0.109 & 1762 & 2667 & 3.66 & 3.79 \\
\hline 7 & 0.208 & 2543 & 1767 & 5.30 & 4.71 \\
\hline 8 & 0.151 & 2055 & 2615 & 4.21 & 4.93 \\
\hline 9 & 0.160 & 1753 & 1977 & 4.27 & 4.65 \\
\hline 10 & 0.106 & 2505 & 1539 & 4.68 & 2.15 \\
\hline 11 & 0.224 & 2449 & 1702 & 5.03 & 4.26 \\
\hline 12 & 0.192 & 2552 & 2088 & 4.81 & 4.21 \\
\hline 13 & 0.254 & 1961 & 1737 & 5.18 & 5.08 \\
\hline 14 & 0.257 & 1453 & 1237 & 4.50 & 4.42 \\
\hline 15 & 0.268 & 2709 & 1661 & 6.28 & 4.79 \\
\hline 16 & 0.205 & 2262 & 1218 & 5.22 & 2.89 \\
\hline 17 & 0.393 & 1858 & 2182 & 4.54 & 9.22 \\
\hline 18 & 0.357 & 1717 & 1463 & 6.30 & 6.50 \\
\hline Mean \pm SD & $0.190 \pm 0.062$ & $2153 \pm 512$ & $2056 \pm 548$ & $5.00 \pm 1.14$ & $4.49 \pm 1.59$ \\
\hline
\end{tabular}

a $p<0.05$ compared to control subjects

Type 1 diabetic subjects with control subjects on the basis of HDL cholesterol. Consequently it is inappropriate to draw conclusions relative to the absolute values for plasma lipids and lipoproteins in normal health and Type 1 diabetes from these data. Broad similarities in apo A kinetics were observed in the control subjects and Type 1 diabetic patients particularly in the way apo A-I and A-II were regulated by catabolism and synthesis, respectively. However, significant differences between the two groups indicated that Type 1 diabetes is associated with a distinct derangement in HDL metabolism. Although no gross abnormalities were observed in the mean levels of lipids, lipoproteins and lipolytic enzymes in the Type 1 diabetic men, the interrelationships between these parameters were altered. Whereas the control subjects showed a predictable inverse association between VLDL triglyceride and HDL cholesterol this correlation was absent in the Type 1 diabetic subjects. In fact, VLDL triglyceride showed little variation within the latter group as a whole. The question arises if the narrow range of trigly- cerides was due to the patient selection or if it was a consequence of good glycaemic control in Type 1 diabetes. We believe the latter to be the case. In the present study the majority of the patients ( 9 of 17) actually had $\mathrm{HbA}_{1}$ within the normal range and only three subjects had values exceeding the upper normal range by $2 \%$. Thus, our patients had very good or moderate glycaemic control. These data accord with the observation that overall serum total and VLDL triglycerides are commonly subnormal in Type 1 diabetic patients with good glycaemic control due to decreased transport rates of VLDL particles [10]. The metabolic link between VLDL triglyceride and HDL cholesterol is mediated in part by LPL $[8,39$, 40]. Note that in the control subjects, as HDL cholesterol rises and VLDL triglyceride falls, there is a progressive increment in LPL activity in the plasma. This three-way relationship is again disrupted in Type 1 diabetes. So these preliminary observations suggest that conventionally insulin-treated insulin-dependent diabetes may compromise the link between lipoprotein lipase activity, 

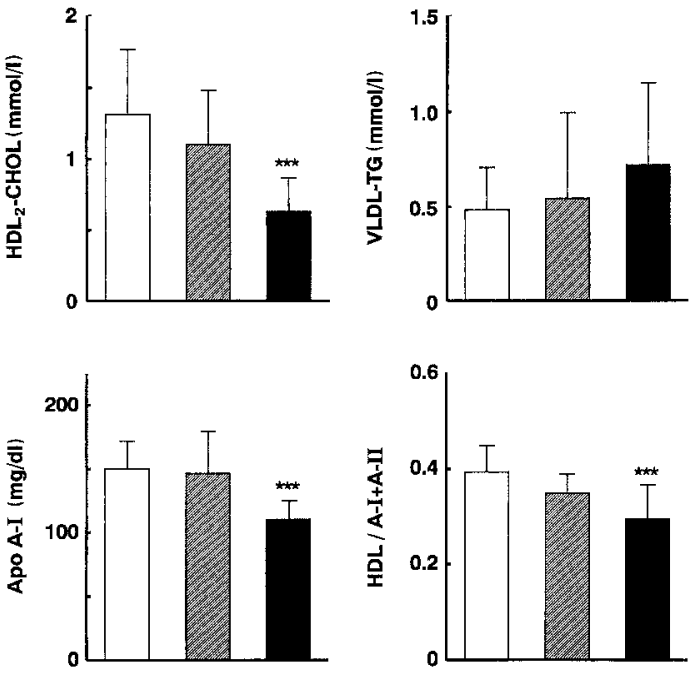

Fig. 3. The concentrations of $\mathrm{HDL}_{2}$ cholesterol ( $\mathrm{HDL}_{2}-\mathrm{CHOL}$ ), VLDL triglycerides (VLDL-TG) and apo A-I and HDL/A-I + A-II ratio by $\mathrm{Lp} A-\mathrm{I}$ fractional catabolic rate (FCR) tertiles for all 35 individuals studied ( $n=17$ for Type 1 (insulin-dependent) diabetic men, $n=18$ for non-diabetic men). Open bars represent highest tertiles, hatched bars medium tertiles and black bars lowest tertiles of $\mathrm{HDL}_{2}$ cholesterol, $* * * p<0.001$ compared to the highest tertile of Lp A-I FCR

VLDL metabolism and circulating HDL cholesterol concentrations.

In the two groups (as a result of selection) plasma total apo A-I concentrations, rates of synthesis and fractional catabolism were the same. However, the rate of apo A-II synthesis in the Type 1 diabetic group was reduced $22 \%$, resulting in a decrement (although non-significant) in the plasma concentration of this apoprotein. Therefore in Type 1 diabetes there appears to be a further dislocation between apo A-I and apo A-II metabolism. Since we know that apo A-I resides in HDL in two distinct particle species, only one of which contains apo A-II $[22,27,30$ 32], these data imply that Type 1 diabetes has a differential impact on these two species. Consequently, we proceeded to multicompartmental analysis using the model shown in Figure 1. This approach provided an explanation for the observations that the clearance rate of apo A-I relative to apo A-II depended on the apo A-I/A-II ratio in both non-diabetic and Type 1 diabetic groups. Total plasma apo A-I rises in control subjects and Type 1 diabetic patients due primarily to a decrement in LpA-I catabolism. LpA-I/A-II particles are much less affected both in terms of mass and turnover. Thus, increases in HDL $\left(\mathrm{HDL}_{2}\right)$ cholesterol in both control and Type 1 diabetic subjects derive primarily from reduced catabolism of LpA-I particles. This substantiates the results of our earlier work $[22,23]$ and confirms the findings of Brinton, Eisenberg and colleagues $[6,7]$ who demonstrated significant negative associations between HDL cholesterol and the rate of A-I clearance. Brinton et al. [7] have pointed out that as HDL cholesterol rises so does particle size (as calculated on the basis of HDL cholesterol/A-I + A-II ratio). This in turn is associated with decreased particle clearance. Our data confirm and extend this observation by suggesting that the effect is focused primarily on LpA-I.
The present data also show that the plasma concentration of the LpA-I/A-II particle is primarily dependent on its rate of synthesis, which according to our model is reduced in Type 1 diabetic individuals. In this context it is well-known that Type 1 diabetic patients with good to fair glycaemic control have low VLDL triglyceride due to the suppression of VLDL secretion [11,41, 42]. Whether this is due to reduced flux of non-esterified fatty acids to the liver or to alterations in portal insulin concentration is open to question [10]. The lack of correlation between plasma VLDL triglyceride and LPL activity in Type 1 diabetes suggests that in this condition VLDL synthesis may be a more important regulator of VLDL concentration than the removal. LpA-I/A-II particles thought to be synthesised in the liver [44], may be influenced in the same way as VLDL synthesis. Indeed, an association between apo A-II and VLDL apo B synthesis has been previously noted by Magill et al. [45]. Thus, if VLDL triglycerides and/or apo B stimulates the synthesis of Lp A-I/A-II particles a reduction of VLDL synthesis would be followed by a fall of Lp A-I/A-II output. Another possibility is that

\section{Non-diabetic men}
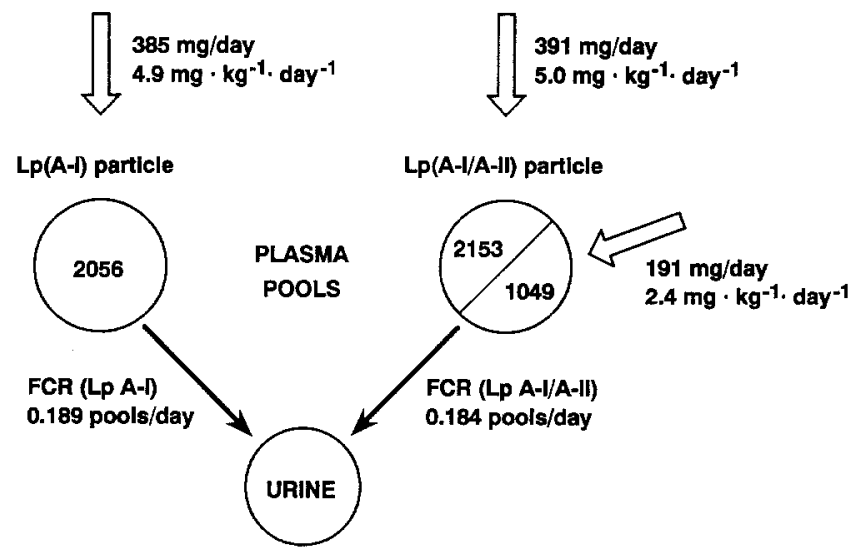

Type 1 (insulin-dependent) diabetic men
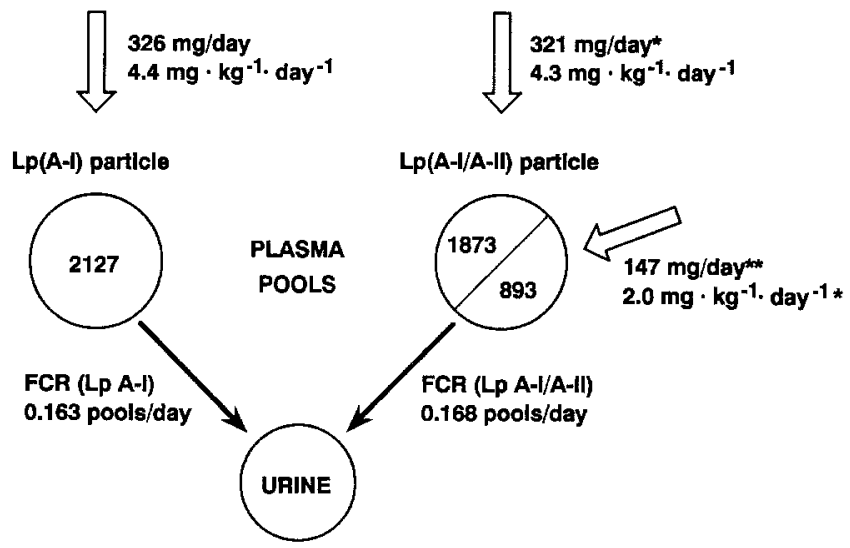

Fig. 4. Data for lipoprotein (Lp) A-I and Lp A-I/A-II kinetics derived from multicompartmental analysis using the model presented in Figure $1 . * 0<0.05, * * p<0.01$ for differences of diabetic men compared to non-diabetic men. FCR indicates fractional catabolic rate 

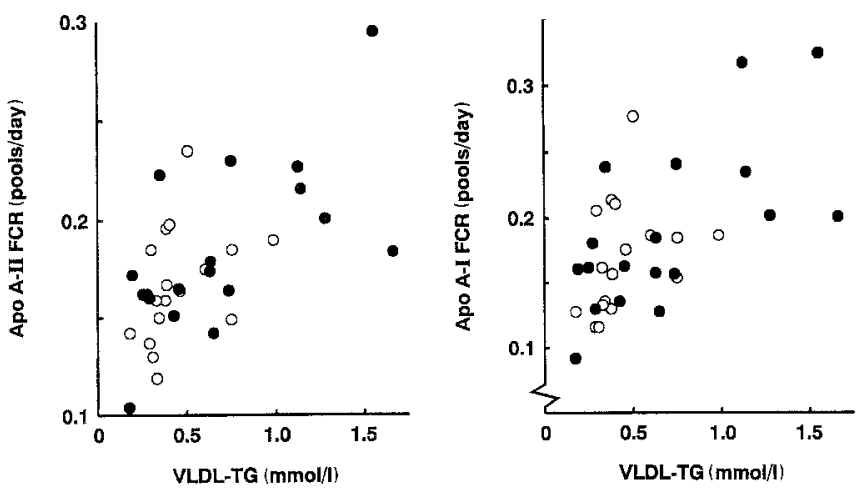

Fig.5. Left panel shows interrelationships between fractional catabolic rate (FCR) of apolipoprotein (apo) A-II and VLDL triglyceride (VLDL-TG) in control men $(\bullet)(r=0.65, p<0.01)$ and in Type 1 (insulin-dependent) diabetic men $(O)(r=0.39$, NS). Right panel shows interrelationship between FCR of apo A-I and VLDL triglycerides (VLDL-TG) in control men $(r=0.66, p<0.01)$ and in Type 1 (insulin-dependent) diabetic men $(r=0.34$, NS)

decreased flux of non-esterified fatty acids into the liver in conventionally insulin-treated Type 1 diabetic patients with good glycaemic control modulate Lp A-I/A-II particle synthesis. We argue above that in Type 1 diabetes there is a disruption in the normal association between VLDL triglyceride and HDL metabolism. In non-diabetic individuals plasma triglyceride is positively associated with the fractional clearance rate of both apo A-I and apo A-II as noted earlier by several groups. Brinton et al. [7] have suggested that this link depends on (1.) the relative activities of LPL and HL and, (2.) the concentration of VLDL triglyceride. This concept is supported by the observations of Goldberg et al. [46] who found that in monkeys LPL inhibition increased the FCR of apo A-I markedly. The data suggest that variations in apo A-I FCR may be due to differences in LPL activity. In our studies there was an inverse correlation between LPL activity and FCR's of apo A-I and apo A-II in the control group but not in the Type 1 diabetic group. Where VLDL triglyceride is high and LPL is low, HDL, as a result of neutral lipid exchange, becomes triglyceride-rich and a better substrate for HL which reduces its size and hence promotes its clearance. Our data suggest that this mechanism does not contribute to the low HDL levels in our Type 1 diabetic subjects. In those with a low HDL cholesterol, low apo A-I and high LpA-I clearance, other mechanisms independent of the VLDL-lipoprotein lipase link must operate. This study indicates that HDL metabolism remains largely intact in Type 1 diabetes, however, consistent differences were observed whose origins may lie in the necessity to treat Type 1 diabetic subjects with large doses of exogenous insulin.

Acknowledgements. This work was supported by grants from the Finnish State Medical Research Council, the Sigrid Juselius Foundation and the Aarne Koskelo Foundation, Helsinki, Finland and the British Heart Foundation (89/107) and the Scottish Hospitals Endowment Research Trust (SHERT 992) in the U.K. We acknowledge the excellent technical assistance of Ms. H.Hilden and Ms. S. Rannikko. We are also grateful for the secretarial assistance provided by Ms. R. Selivuo and Ms. M.Puupponen. This work was presented at the 50th Annual Meeting of the American Diabetes Association, Atlanta, USA, 1990.

\section{References}

1. Gordon DJ, Rifkind BM (1989) High-density lipoprotein - the clinical implications of recent studies. $\mathbf{N}$ Engl J Med 321: 13111316

2. Nikkilä EA, Kuusi T, Taskinen M-R (1982) Role of lipoprotein lipase and hepatic endothelial lipase in the metabolism of high density lipoproteins: a novel concept on cholesterol transport in HDL cycle. In: Carlson LA, Pernow B (eds) Metabolic risk factors in ischemic cardiovascular disease. Raven Press, New York, pp 205-215

3. Tall AR (1990) Plasma high density lipoproteins: metabolism and relationship to atherogenesis. J Clin Invest 86:379-384

4. Schaefer EJ, Ordovas JM (1986) Metabolism of apolipoproteins A-I, A-II and A-IV. Meth Enzym 129: 420-443

5. Fidge N, Nestel P, Ishikawa T, Reardon M, Billington T (1980) Turnover of apoproteins A-I and A-II of high density lipoprotein and the relationship to other lipoproteins in normal and hyperlipidemic individuals. Metabolism 29: 643-653

6. Brinton EA, Eisenberg S, Breslow JL (1989) Elevated high density lipoprotein cholesterol levels correlate with decreased apolipoprotein A-I and A-II fractional catabolic rate in women. J Clin Invest 84: 262-269

7. Brinton EA, Eisenberg S, Breslow JL (1991) Increased apo A-I and A-II fractional catabolic rate in patients with low high density lipoprotein-cholesterol levels with or without hypertriglyceridemia. J Clin Invest 87: 536-544

8. Nestel PJ (1987) High-density lipoprotein turnover. Am Heart J 113:518-521

9. Le A-G, Ginsberg HN (1988) Heterogeneity of apolipoprotein A-I turnover in subjects with reduced concentrations of plasma high density lipoprotein cholesterol. Metabolism 37: 614-617

10. Taskinen M-R (1990) Hyperlipidaemia in diabetes. Baill Clin Endocrin Metab 4: 743-775

11. Schernthaner G, Kostner GM, Dieplinger H, Frager R, Mühlhauser I (1983) Apolipoproteins (A-I, A-II, B), Lp(a) lipoprotein and lecithin: cholesterol acyltransferase activity in diabetes mellitus. Atherosclerosis 49: 277-293

12. Briones ER, Mao SJT, Palumbo PJ, O'Fallon WM, Chenoweth W, Kottke BA (1984) Analysis of plasma lipids and apolipoproteins in insulin-dependent and noninsulin-dependent diabetics. Metabolism 33: $42-49$

13. Mattock MB, Salter AM, Fuller JH, Omer T, El-Gohari R, Redmond SD (1982) High density lipoprotein subfractions in insulindependent diabetic and normal subjects. Atherosclerosis 45: $67-79$

14. Taskinen M-R, Kuusi T, Nikkilä EA (1985) Regulation of HDL and its subfractions in chronically insulin treated patients with type 1 diabetes. In: Crepaldi G, Tiengo A, Baggio G (eds) Diabetes, obesity and hyperlipidemias. Elsevier, Amsterdam, pp 251-259

15. Laakso M, Pyörälä K, Sarlund H, Voutilainen E (1986) Lipid and lipoprotein abnormalities associated with coronary heart disease in patients with insulin-dependent diabetes mellitus. Arteriosclerosis 6:679-684

16. Winocour PH, Durrington PN, Ishola M, Anderson DC (1986) Lipoprotein abnormalities in insulin-dependent diabetes mellitus. Lancet I: $1176-1178$

17. Eckel RH, Albers JJ, Cheung MC, Wahl PW, Lindgren FT, Bierman EL (1981) High density lipoprotein composition in insulindependent diabetes mellitus. Diabetes 30: 132-138

18. Ewald U, Tuvemo T, Vessby B, Walinder O (1982) Serum apolipoproteins A-I, A-II and B in diabetic children and matched healthy controls. Acta Paediatr Scand 71: 15-18

19. Bittolo Bon GB, Cazzolato G, Avogaro P (1984) Lipids, lipoproteins and apolipoproteins in type 1 (insulin-dependent) and 
type 2 (non-insulin-dependent) diabetes mellitus. Acta Diabetol Lat 21:315-324

20. Nikkilä EA (1981) High density lipoproteins in diabetes. Diabetes 30 [Suppl 2]: 82-87

21. Shepherd J, Gotto AM, Taunton DO, Caslake MJ, Farish E (1977) The in vitro interaction of human apolipoprotein A-I and high density lipoproteins. Biochim Biophys Acta 489: 486-501

22. Atmeh RF, Shepherd J, Packard CJ (1983) Subpopulations of apolipoprotein A-I in human high-density lipoproteins their metabolic properties and response to drug therapy. Biochim Biophys Acta 751: 175-188

23. Shepherd J, Packard CJ, Gotto AM, Taunton DO (1978) A comparison of two methods to investigate the metabolism of human apolipoproteins A-I and A-II. J Lipid Res 19: 656-661

24. Havel RJ, Eder HA, Bragdon JH (1955) The distribution and chemical composition of ultracentrifugally separated lipoproteins in human serum. J Clin Invest 34: 1345-1353

25. Huttunen JK, Ehnholm C, Kinnunen PJ, Nikkilä EA (1975) An immunochemical method for selective measurement of two triglyceride lipases in human postheparin plasma. Clin Chim Acta 63: 335-347

26. Berman M, Weiss MF (1974) SAAM Manual. Washington DC: US Government Printing Office. (US PHS publ no. 1703)

27. Cheung MC, Albers JJ (1984) Characterization of lipoprotein particles isolated by immunoaffinity chromatography. J Biol Chem 259: 12201-12209

28. Zech LA, Schaefer EJ, Bronzert TJ, Aamodt RL, Brewer HB (1983) Metabolism of human apolipoproteins A-I and A-II: compartmental models. J Lipid Res 24: 60-71

29. Norfeldt PP, Olofsson SO, Fager G, Bondjers G (1981) Isolation and partial characterization of the lipoprotein families $A$ and A-I from high-density lipoproteins of human serum. Eur J Biochem 118: $1-8$

30. Koren E, Puchols P, Alaupovic P, Fesmire J, Kandoussi A, Fruchart J-C (1987) Quantification of two different types of apolipoprotein A-I containing lipoprotein particles in plasma by enzyme-linked differential-antibody immunosorbent assay. Clin Chem 33: 38-43

31. Cheung MC, Segrest JP, Albers JJ et al. (1987) Characterization of high density lipoprotein subspecies: structural studies by single vertical spin ultracentrifugation and immunoaffinity chromatography. J Lipid Res 28: 913-929

32. Cheung MC, Wolf AC (1988) Differential effect of ultracentrifugation on apolipoprotein A-I-containing lipoprotein subpopulations. J Lipid Res 29: 15-25

33. Grow TE, Fried M (1975) Lipoprotein geometry: spatial relationships of human HDL apoproteins studies with a bifunctional reagent. Biochem Biophys Res Comm 66: 352-356

34. Desbuquios B, Aurbach GD (1971) Use of polyethylene glycol to separate free and antibody-bound peptide hormones in radioimmunoassays. J Clin Endocrinol Metab 33: 732-738
35. Heding LG (1971) Radioimmunological determination of pancreatic and gut glucagon in plasma. Diabetologia 7: 10-19

36. Welch SG, Boucher DJ (1978) A rapid micro-scale method for the measurement of haemoglobin $A_{1}(a+b+c)$. Diabetologia 14: 209-211

37. Johnson RN, Metcalf PA, Baker JR (1983) Fructosamine: a new approach to the estimation of serum glycosylprotein. An index of diabetic control. Clin Chim Acta 127: 87-95

38. Dixon WJ (1981) BMDP statistical software. University of California Press, Los Angeles

39. Nikkilä EA, Taskinen M-R, Sane T (1987) Plasma high-density lipoprotein concentration and subfraction distribution in relation to triglyceride metabolism. Am Heart J 113: 543-548

40. Eisenberg S, Brinton EA, Breslow JL (1990) Triglyceride and high density lipoprotein. In: Carlson LA (ed) Disorders of HDL. Smith-Gordon, London, pp 127-132

41. Pietri AO, Dunn FL, Grundy SM, Raskin P (1983) The effect of continuous subcutaneous insulin infusion on very-low-density lipoprotein triglyceride metabolism in type I diabetes mellitus. Diabetes 32: 75-81

42. Dunn FL, Carroll PB, Beltz WF (1987) Treatment with artificial $\beta$-cell decreases very-low-density lipoprotein triglyceride synthesis in type I diabetes. Diabetes 36: 661-666

43. Rosenstock J, Vega GL, Raskin P (1988) Effect of intensive diabetes treatment on low-density lipoprotein apolipoprotein B in type I diabetes. Diabetes 37: 393-397

44. Brewer HB, Rader D, Fojo S, Hoeg JM (1990) Frontiers in the analysis of HDL structure, function, and metabolism. In: Carison LA (ed) Disorders of HDL. Smith-Gordon, London, pp 51-58

45. Magill P, Rao SN, Miller NE et al. (1982) Relationships between the metabolism of high-density and very-low-density lipoproteins in man: studies of apolipoprotein kinetics and adipose tissue lipoproteins lipase activity. Eur J Clin Invest 12: 113-120

46. Goldberg IJ, Blaner WS, Vanni TM, Moukides M, Ramakrishnan R (1990) Role of lipoprotein lipase in the regulation of high density lipoprotein apolipoprotein metabolism. J Clin Invest 86 : $463-473$

Received: 23 September 1991

and in revised form: 22 November 1991

Dr. M.-R. Taskinen

Third Department of Medicine

University of Helsinki

Haartmaninkatu 4

SF-00290 Helsinki

Finland 